\title{
Digital and Conventional Matchmaking - Similarities, Differences and Tensions
}

\author{
Frida Ivarsson \\ University of Gothenburg \\ Swedish Center for Digital Innovation \\ frida.ivarsson@ait.gu.se
}

\author{
Fredrik Svahn \\ University of Gothenburg \\ Swedish Center for Digital Innovation \\ fredrik.svahn@ait.gu.se
}

\begin{abstract}
Matchmaking is a process of complex resource allocation where firms are intermediaries of supply and demand between actors in an ecosystem. Digital platforms have brought matchmaking into the spotlight in IS research by their ability to scale and improve the quality of matching. In this paper, we outline four principles of digital matchmaking from digital platform theory. We continue by illustrating these principles in an empirical case-study of conventional matchmaking in the Swedish forest industry. We seek to improve the understanding of matchmaking by identifying similarities and differences of digital and conventional matchmaking. We then discuss tensions that may emerge for the conventional matchmaker facing digitalization. We contribute to theory of changing organizing logic associated with digital technology adoption and to practice by outlining what it takes becoming a digital matchmaker.
\end{abstract}

\section{Introduction}

In the wakes of digitalization, there is a growing interest in matchmaking [19]. This is largely triggered by the opportunities afforded by digital platforms. Matchmakers position themselves between actors with the intent to intermediate transactions. Matchmaking is a process of complex resource-allocation, facilitating transactions between actors [27], but also increasing the quality of matching supply with demand. It essentially improves "who gets what and why" [50].

Digital platforms are essentially technological artifacts for matchmaking, consisting of an "extensible codebase to which complementary third-party modules can be added" [12]. Consider as an illustrative example the digital platform of Uber. It facilitates matchmaking by connecting vehicle owners and people demanding services such as car, cargo, take away food or health care transportation [41]. In 2018, only 9 years after its foundation, Uber connected 3 million drivers with 75 million users demanding transportation services ${ }^{1}$. The Uber example illustrates that digital platforms allow for highly efficient scaling of matchmaking, ultimately enabling powerful network effects [57, 59, 46, 33].

To understand matchmaking, IS scholars have largely focused on "digital natives", like Uber [9, 36, 29], and manufacturing firms, such as Volvo Cars, layering physical products with digital platforms $[65$, 56]. The adoption of platform logic in conventional matchmaking has been less explored. Conventional matchmakers were founded in traditional industrial arrangements, now facing digitalization as a potential threat [6]. The US wheat market is a salient historical example where transactions between growers and bakers were managed by human agents up until the 19th century when standardized, anonymous exchange was introduced [50]. This knowledge gap is unfortunate in light of how extant theory point to the difficulties of adapting to technological change [35, $26,62]$ and how digital technology adoption is accompanied with changing organizing logic [52, 64]. Studying conventional matchmakers is therefore a particularly interesting research venture. First, it opens up for learning about what is means "becoming digital" by focusing on organizing for matchmaking. Second, we are offered a rare opportunity to learn about identity-related challenges by studying how conventional matchmakers adopt "matchmaking technologies" [60].

In this paper, we aim for improved understanding of matchmaking by exploring the preconditions of digital matchmaking in a conventional matchmaker firm in the Swedish forest industry, Sydved AB. The firm intermediates raw material transactions between forest owners and mills in the southern parts of

${ }^{1}$ Business of apps (2019) 
Sweden. The matchmaking agents in this market is primarily the forest buyers, focused on building and nurturing relationships to secure contracts. The central practice of these professionals is the intriguing art of getting 'under the skin' of forest owners; identifying and respecting incentives behind forest ownership, understanding their practical challenges and offering various services addressing these challenges. In contrast to ecosystems connected with digital platforms, where matchmaking is a matter of digital technology development and use [59, 15, 25], Sydved's matchmaking is human enabled and situated within a strongly-tied, forestry-specific ecosystem.

To learn about 'becoming digital' and the associated identity challenges (referring to insider and outsider perceptions of what is fundamental of an organization [60]), we analyze this rich empirical account of conventional matchmaking through an organizing logic framework of digital matchmaking. The framework is constructed from extant research on digital platforms and articulates four organizing principles for digital matchmaking; relationship building, mobilizing for innovation, governing transactions and curating matches. We thereby seek a better theoretical understanding of (1) similarities between conventional and digital matchmaking, (2) how conventional matchmaking differs from digital, and (3) what tensions that are likely to unfold during digitalization of matchmaking.

\section{Matchmaking}

As firms engage in matchmaking, they intermediate supply and demand between externally located actors [18]. In this sense, matchmaking is a process of complex resource-allocation, rather than management of single transactions [27]. Matchmakers have been studied as hub firms [14], orchestrators [36, 40] and brokers [38], but the phenomenon did not catch the attention of IS researchers until post-Internet evolution [19]. Still, they have been around for centuries. Historical examples can be found in domains such as coffee [50], agriculture, wool and textile [28], facilitating both transactions and innovation by being intermediaries of knowledge exchange and technological improvement.

Matchmaker firms are different from the typical 'pipeline' firms we have studied in management for over a century [46]. While the logic guiding 'pipeline' firms (designing, producing and selling products) has traditionally been illustrated as a linear value chain [47], the logic of a matchmaker firm is different. Matchmaking does not involve refinement of resources. Contrary to the ability of the 'pipeline' firm of stimulating economies of scale in supply, i.e. in production, matchmaker firms may stimulate economies of scale in demand [46]. This is because matchmaker firms are powered by network effects $[19$, 46] where the demand of one actor depends on the demand of another [17]. Network effects occur when the value of a product or services increases with the number of others using it [33]. If a matchmaking firm is capable of staging such a recursive and selfreinforcing process, within one class of users (direct network effects) or across different user groups (crossside network effects), it has created a strong position for value creation and capture of a share of that value. Research has shown that these firms outperform other firm types on growth rate and profit margin, an effect due to significant reduction of marginal costs [36].

Matchmaker firms operate in ecosystems, i.e. multilateral networks of actors dependent on each other for the prosperity of the collective [30]. Their shared prospect might be in a digital platform but need not be. Ecosystems include a wide array of heterogeneous actors such as partnering firms, communities, third-party innovators, government agencies, social movements etc. The literature contains different classes of ecosystems, for example; business ecosystems [39], innovation ecosystems [1, 11], digital ecosystems [53] and platform ecosystems [16, 59]. Relationships in ecosystems are characterized by interdependency [31] with no clear distinction of competition and collaboration [5].

It is suggested that matchmaking can be enabled by two distinct forms of transaction modes (see Figure 1); orchestration or brokering [22]. In brokering, the matchmaker takes on an active role in matchmaking between actors (for example real estate brokering). To secure its own influence, it intentionally keeps actors somewhat separated and forced to interact indirectly through the matchmaker firm. Practicing orchestration, the matchmaker encourages direct interaction between previously disconnected actors (for example a shopping mall). Lacking explicit control mechanisms in orchestration [14], matchmaker firms need to explore the extrinsic and intrinsic motivations of actors to incentivize participation in economic activity [4].

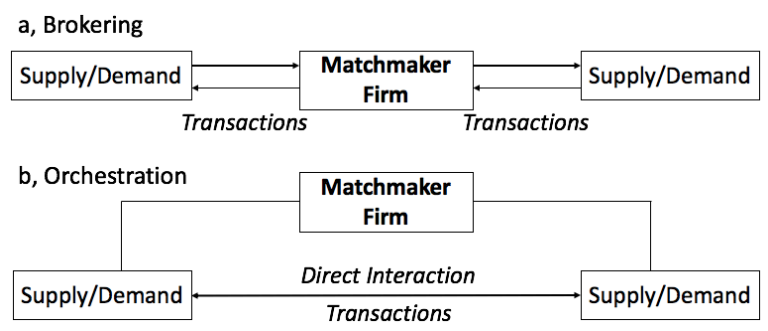

Figure 1. Brokering vs orchestration [27]. 


\section{Digital Matchmaking}

Digital platforms are technological artefacts developed and used for digital matchmaking [19]. Platforms can be viewed through an economic perspective as multi-sided markets or through an engineering perspective as architectures [23]. We refer to digital platforms as technological artifacts with "an extensible codebase to which complementary thirdparty modules can be added" [12].

Adopting digital technology typically triggers change in organizing logic $[64,52]$. In this context, logic refers to the organizing principles, including both material practices and symbolic constructions that guide and legitimize action [20,58]. While logic provides stability, being a shared pattern of reasoning including assumptions, beliefs and values, it may also be a source of tension, as new ways of organizing are likely to be in conflict with old ones. Such tensions have been identified in a wide range of domains such as healthcare $[10,3]$, government/research agencies (NASA) [2], the computer industry [24] and the automobile industry [56].

Organizations may consequently incorporate plural logics [42]. This plurality can be traced to distinct professions, sharing tasks and backgrounds [3]. Thereby, perspectives on digital technology can differ. For example, software developers tend to adopt an engineering perspective on digital platforms, while managers adopt a market logic [48]. To manage potential tensions between co-existing logics, organizations can introduce mechanisms for collaboration between actors with different backgrounds [49] and foster legitimacy by selectively coupling shared elements of different logics [42]. We now derive an organizing logic framework, based on four principles for digital matchmaking; relationship building, mobilizing for innovation, governing transactions and curating matches.

\subsection{Relationship Building}

With the purpose to stimulate positive network effects, digital matchmaking is about relationship building. Users must be attracted to the platform [46]. First, digital matchmakers pursue this by reducing barriers for usage. For example, frictionless entry allows users "to quickly and easily join a platform and begin participating in the value creation that the platform facilitates" [45], By subsidization, matchmakers can attract price-sensitive actors [19]. Second, digital matchmakers experiment continuously with various mechanisms for promoting engagement. Side-switch allows individual actors to easily play multiple roles on the platform. Feedback loops can improve the user experience on an on-going basis by learning from past usage of actors [46]. Further, matchmakers may promote user engagement by allowing them to generate content on their own [46]. For example, Spotify was originally viewed as a platform for advertisement but provided music created by independent artists for attracting users [54]. Third, digitally mediated relationships are depersonalized and are managed at "arms-length" [22]. Therefore, reducing perceived risk associated with a "faceless" interaction on the digital platform is necessary [43]. For example, AliBaba did this by providing credit verification, identity authentication and exposing third-parties' experience of past transactions [57]; TripAdvisor implemented a ranking system based on user reviews [32] and Uber offered the opportunity to rate experiences of other users [19] on the platform.

\subsection{Mobilizing for Innovation}

Digital matchmaking is about mobilizing a wide range of actors for novel forms of value creation over time, i.e. becoming multisided [19]. In doing so, digital matchmakers can promote generative exploration $[66,55]$ that makes platforms spur further innovation. As a consequence, the technological architecture of a digital platform is evolving over time. The digital matchmaker can do this by launching open architectures, i.e. mobilizing external developers to the platform [44]. For example, firms can provide boundary resources such as APIs and software development kits for actors to explore [25]. Note that the opportunities to side-switch makes the distinction between developer/user or producer/consumer somewhat artificial [46]. Secondly, digital matchmakers can explore more peripheral relationships by establishing cross-industry collaboration with actors sharing interests in the platform [53]. An illustrative example is Mastercard's choice of partners with complementary data, involving PizzaHut LLC and SoftBank Corp [22].

\subsection{Governing Transactions}

Digital matchmaking is essentially about enabling orchestration where actors interact and transact autonomously through the digital platform [57, 4]. Transactions can include for example physical resources (e.g. Amazon), services (Uber), social exchange (Facebook), economic value (cryptocurrency platforms), knowledge (Wikipedia), and data as inevitably transacted on any digital platform. Still, matchmakers seek to capture a share of the transacted value. For example, Uber governs value capture by pricing [19] and controlling user data for 
spurring further innovation [41]. More precisely, digital matchmaking enables dynamic pricing, that reflect prevailing supply and demand in a particular point in time [9]. Given this distributed agency, governance is about architectural control rather than organizational control [34]. See for example how Uber's adoption of a smartphone interface enables labor supply and access to cars from independent vehicle owners [9, 41]. Consequently, control on digital platforms rely on alternatives to contract law as deployed in traditional hierarchies (i.e. employments) in favor of such as for example licensing or incentivizing ecosystem actors for usage $[13,4]$. It is important to note that brokering still plays a role in digital matchmaking, particularly the control of data (which has raised concerns about integrity) [46].

\subsection{Curating Matches}

The essence of digital matchmaking is improving the quality of matching (i.e. "who gets what and why") [50]. Scaling may complicate this process as complexity increases, creating so called negative network effects [46]. Digital matchmakers manage complexity through curation, typically through implementing software-based algorithmic matching $[40,36]$. The power of algorithmic matching has been demonstrated by comparing the performance of the human-edited Yahoo database of web-pages and Google's page rank algorithm [46]. Resultingly, growth patterns may become exponential as the marginal cost of transactions on the platform decreases $[40,46]$. Roth et al. [51] offer an example on curation of physical resources, where algorithmic matchmaking in kidney exchange between organ donors and patients increased both healthcare efficiency and welfare gains [51, 50]. However, successful algorithmic identification of actors' preferences/access to resources takes high quality data [29]. Through data analytics [8] of actors' previous behavior/transactions (or actors with similar preferences), firms can improve knowledge on what constitutes a qualitative match for a particular actor.

\section{Research method}

\subsection{Data Collection and Analysis}

This research paper is based on an on-going indepth case study $[61,63]$ of a conventional matchmaker firm in the Swedish forest industry, Sydved AB. At present time (2019-05-30), the first author has actively engaged with the firm [37] by spending 65 days (494 hours) on site, participated in
46 meetings as both observer and active participant, conducted 57 interviews (including management, forest buyers, IT, marketing etc. and both semi- and unstructured form), accessed 166 documents (strategy documents, historical records, meeting notes, internal/external presentations etc.), consuming marketing content of the firm (for example the Sydved magazine and Instagram page). Data are recorded through field notes, photos and transcribed audio recordings.

We used Atlas.TI for analyzing our data. To build solid links to theory, we decided to code the dataset and related literature (on digital platforms and ecosystems) together in the same hermeneutic unit. Over several iterations, we shifted from open to selective coding [7], gradually applying the matchmaking lens [19]. We then used the coding relations to create a network view, disclosing patterns of similarity (e.g. relationship building in the codes "social relationship management" and "technology mediated relationships"). We condensed our findings into four distinct principles due to some overlap. When adding associated codes to the network view, we were able to identify differing elements which constitute the basis of our discussion. We eventually structured the paper on the basis of this final coding; first we outline the logic for digital matchmaking based on digital platform theory, then we return to the data for illustrating the principles empirically.

\subsection{Case Selection}

There are three motivations for why the Sydved case is suitable for our research purposes. First, the Swedish forest raw material market is intrinsically fitted for matchmaking. There are tens of thousands forest owners, ranging from very small, private owners to giants such as government and church. There are also a number of giant paper mills and many smallscale saw mills, demanding raw material. This market is thus signified by fragmentation, diversity, and little centralized governance. Second, the case firm Sydved is a conventional matchmaker in that they coordinate transactions amongst a wide range of complementary ecosystem actors, including forestry service suppliers (i.e. machine operators), plant suppliers and transporters. Third, Sydved in particular and the Swedish forest industry in general are in the early stages of digitalization. Digital technologies are generally viewed as tools for increasing efficiency and productivity in forestry, rather than technologies for business development (The Forest Industry's IT Barometer by Tieto, 2018). Sydved therefore presents a preserved and rare opportunity for studying conventional matchmaking. 


\section{The Sydved Case}

Sydved AB was founded in 1979 by four dominant players in the Swedish forest industry and is today owned by Stora Enso Skog AB (2/3 of the shares) and Ahlström-Munksjö $\mathrm{AB}$ (1/3 of the shares). In organizing for matchmaking, Sydved has set up a decentralized organizational structure covering the southern parts of Sweden, divided into regions, districts and individual forest buyer areas. The forest buyers are the firm's "professional matchmakers", making up about $50 \%$ of the workforce. The use of geographically divided forest buyer areas allows for local community building, often in areas where they live themselves.

At Sydved, face to face meetings are deeply valued. The capability for direct and contextualized interaction is understood as a factor making or breaking a business relationship. As illustrated by a 2019 marketing message, it is deeply embedded in the firm's identity: "The forest's unvarnished space is a beautiful and natural place for meetings. Meetings, human to human, without any masks, the same way as when people meet safely in their home environment". To understand how matchmaking in Sydved relates to organizing for digital matchmaking, we now explore the Sydved case through the four principles of matchmaking derived in section 3 .

\subsection{Relationship Building}

Sydved organizes for relationship building by employing skilled forest buyers who (1) seek to form new relationships with forest owners and (2) engage new partner firms who can supply forestry services. Similar to the ancient wheat market [50], relationships are individually managed and dependent on face-toface interactions. Forest owners are typically approached by phone-call, followed by interactions taking place on the forest owners' properties or homes, a conventional tactic for creating awareness [46]. Offering "forestry care" services is a standard nudging tactic for attracting forest owner attention: "I stop the car, I take my phone, I open maps. Then I find my location and look up who owns [the forest property where I am]. I call the person and say "Hey, I was out driving. I noticed you need to weed your forest. I can go back and have a look. Join, if you want. If not, I can go through the property on my own and get back to you with an offer, describing what I think you need to do. It's for free"."

The everyday life of forest buyers is centered on getting 'under the skin' of forest owners; identifying and respecting incentives behind their forest ownership (revenue, environmental protection, family heritage etc.); understanding their current practical challenges (windfalls, flooding, insect attacks etc.); and ultimately, offering value for making their lives easier (e.g., thinning, planting, building roads etc.). Socializing, such as gossiping about local acquaintances over a cup of coffee, is essential for building trust. The great amount of time spent on socializing have rendered forest buyers an internal nickname: "the coffee drinkers". The firm allocates substantial resources for activities such as huntings, barbeques and skiings to strengthen relationships. Beside forest owner interaction, the forest buyers regularly engage with partnering firms, particularly machine operators and transporters. The so called "hut meetings" are recurring events for information exchange and team building. The marketing manager explains: "[our partners] must feel that they are part of a team and that we help them become profitable".

Relationships with saw and paper mills are typically managed by region and logistic managers. Compared to forest buyer interactions, these meetings are more business-oriented, focusing on price negotiations. However, a region manager stresses that socializing should not be underestimated: "You take a cup of coffee together, you spend like half an hour on social stuff. It could be an hour if there's a lot to talk about. [...] It's a deliberate strategy, I'd say. As you get to know one another, you want to know how things are with the other person. You become like colleagues. [...] It sets a tone for the negotiation which is quite pleasant even though we disagree about prices."

\subsection{Mobilizing Innovation}

Sydved was founded to guarantee the supply of forest raw material to paper mills. In their early days, Sydved was a typical two-sided market [17], matchmaking between mills and forest owners. However, new actors have been mobilized over time for enabling novel forms of value creation. Sydved has gradually become a broker in a multisided market [19]. The turn of the millennium marks a historic milestone when employments of machine operators were terminated and they became independent service suppliers. Seeing the innovation potential in multisidedness, Sydved's management implemented an exercise in 2006, where forest buyers were asked to visualize their "personal networks" for identification of new business potential. As a result of the company's focus on industry complementaries, Sydved's ecosystem now includes a wide range of small and medium-sized business. The forestry developer (i.e. business developer) explains: "The services we provide in addition to wood purchase are for example planting, grounding, clearance and so on. To start 
with, we essentially didn't make any profit on this. Initially, [the purpose was to] increase the probability for us to purchase wood". To mobilize innovation Sydved has also engaged with certification agencies, providing standards for environmental protection, aiming for increasing environmental value in suppliers' business operations.

\subsection{Governing Transactions}

Sydved governs transactions by brokering, i.e. purchasing and re-selling raw material and services. Transactions are governed through contracting, as forest buyers are employed and ecosystem actors are managed by partnerships. In fact, capturing a share of the value of transactions is dependent on brokering. It is important for Sydved to make sure that interests are aligned, i.e. preventing direct interactions and business deals between service suppliers and forest owners. Therefore, forest service suppliers are paid on the basis of production. A district manager explains the rationale: "[In this way, our partners] want to operate the machines. [...] If they spend time talking to forest owners, it means that they lose time for operations."

As for the mills, volumes and prices are decided on negotiations beforehand. By predetermined pricing, forest buyers bear this in mind in forest owner negotiations. A forest buyer explains: "I don't just randomly think "Well, I'll just offer 670 SEK per cubic meter". In the back of my mind, I know the price [the region manager] sold the pine timber for to the mills. I also know to which mill to send it. I decided on that when I first visited the property. Then, I check the price this mill offers per cubic meter. Say the price is 680 SEK, I offer [the forest owner] 670 SEK. We need to make some profit, of course."

A complicating factor in matchmaking forest raw materials is that the equilibrium between supply and demand is frequently punctuated. In times of unforeseen events, such as storm-triggered windfalls or insect attacks, supply will outnumber demand. To avoid overproduction, with potentially devastating economic consequences, Sydved has designed a structure for incentivizing employees. Forest buyers have variable salary dependent on both production volume and profit margin. By including margins, management sought a financial incentive for forest buyers in times with lower mill demands, and thus, lesser need to purchase great volumes of wood.

\subsection{Curating Matches}

Ensuring matching quality in matching of forest raw material is a labor-intensive process involving many variables, i.e. wood types, product assortments (timber, pulp, bio fuel material etc.), geometric shape of the tree, tree adaptation (measurements) preferences of industry actors and geographical distances. Addressing this complexity, managers have established an organizational unit for optimizing logistics to support the forest buyers with planning and communication with transport firms. Ensuring that the mills' demand is met is a top priority, where the logistics manager plays an important role by regularly engaging in "raw material meetings". These meetings typically involve planning and estimation of future raw material supply/demand and reporting on critical market factors, such as macropolitical events or weather forecasts. In order to curate matching further, Sydved engages in bartering with competitors' mills. The logistic manager explains: "We try to do as much barter as we can with [our competitors]. We are hardcore competitors [in buying], but once the wood is purchased, we have agreed upon transporting it to the closest industry to save costs and reduce negative environmental impact".

\section{Discussion}

Digital platforms offer unprecedented opportunities for matchmaking in ecosystems. In this paper, we seek to improve the understanding of what it takes becoming a digital matchmaker by articulating similarities and differences of digital and conventional matchmaking. Our research is an attempt to answer some of the lingering questions about digital platforms more broadly, such as questions related to digital organizing. Conventional matchmakers are particularly exposed to digitalization. It is even argued that they are the "the businesses that platforms are actually disrupting" [18]. In light of this, it is remarkable how little we know about conventional matchmakers and how they respond to digitalization. Given limited scholarly interest in "pre-digital" matchmaking [19], we also know little about how the particularities of digital matchmaking relate to conventional matchmaking.

Our study of Sydved suggests that the four principles of organizing logic, theoretically derived from digital platform theory, are generic. However, while each principle represents a distinct and indispensable practice for conventional and digital matchmaking alike, there are fundamental differences in how they are instantiated. During digitalization, a conventional matchmaker may perceive these differences as conflicting (i.e. differing elements in Table 1), potentially becoming sources of tensions [64, 56]. In what follows, we compare organizing logics for matchmaking (Table 1) and elaborate on such tensions. 


\begin{tabular}{|c|c|c|}
\hline Principles & Elements of Conventional Matchmaking & Elements of Digital Matchmaking \\
\hline $\begin{array}{l}\text { Relationship } \\
\text { Building }\end{array}$ & $\begin{array}{ll}\text { - } & \text { Creating Awareness } \\
\text { - } & \text { Offering Value } \\
\text { - } & \text { Building Trust }\end{array}$ & $\begin{array}{ll}\text { - } & \text { Reducing Barriers } \\
\text { - } & \text { Promoting Engagement } \\
\text { - } & \text { Reducing Risk }\end{array}$ \\
\hline $\begin{array}{l}\text { Mobilizing } \\
\text { Innovation }\end{array}$ & $\begin{array}{l}\text { Identifying Complementary } \\
\text { Products and Services }\end{array}$ & $\begin{array}{ll}\text { - } & \text { Promoting Generative Exploration } \\
\text { - } & \text { Launching Open Architectures } \\
\text { - } & \text { Establishing Cross-industry Collaboration }\end{array}$ \\
\hline $\begin{array}{l}\text { Governing } \\
\text { Transactions }\end{array}$ & $\begin{array}{ll}\text { - } & \text { Relying on Brokering } \\
\text { - } & \text { Contracting } \\
\text { - } & \text { Incentivizing Employees } \\
\text { - } & \text { Predetermined Pricing } \\
\end{array}$ & $\begin{array}{ll}\text { - } & \text { Enabling Orchestration } \\
\text { - } & \text { Licensing } \\
\text { - } & \text { Incentivizing Ecosystem Actors } \\
\text { - } & \text { Dynamic Pricing }\end{array}$ \\
\hline $\begin{array}{l}\text { Curating } \\
\text { Matches }\end{array}$ & $\begin{array}{ll}\text { - } & \text { Optimizing Logistics } \\
\text { - } & \text { Bartering with Competitors }\end{array}$ & $\begin{array}{ll}\text { - } & \text { Algorithmic Matching } \\
\text { - } & \text { Data Analytics }\end{array}$ \\
\hline
\end{tabular}

Table 1. Organizing Logics for Matchmaking

Relationship Building. Ecosystems are distributed and loosely coupled structures, where relationship building is typically focused on the identification and exploitation of mutual interests [32]. Our study suggests that conventional matchmakers address this relationship-building by regularly engaging in face to face meetings with ecosystem actors by creating awareness of firm existence, offering value by addressing actors' underlying motivations and needs and building trust by mirroring socializing practices of the local sociocultural context in which they are situated. Forest buyers are often deeply intertwined with local communities, as forest owners or hunting partner, resulting in a strongly tied ecosystem. The coffee drinking and hunting appear to bear cultural significance in this community, exemplifying how professional matchmakers need to embody such symbols for gaining legitimacy. This indicates that creating a shared identity across firm boundaries is essential in conventional matchmaking. At Sydved the shared identity is inscribed not only in the firm, but in that most forest buyers literally "live their job".

In digital matchmaking, exploiting mutual interests and community building are typically left for platform users to sort out themselves. Rather, the role of the digital matchmaker is to attract users to the digital platform by reducing barriers, promoting engagement and reducing perceived risk of usage. In this sense, digital matchmakers do not seek to reflect any particular sociocultural context but to promote diversity of self-organizing communities [4]. Neither is relationship building geographically bounded. In digitalization of a conventional matchmaker, this means that the professional matchmaker (forest buyer) is particularly exposed. In digital organizing for relationship building, management become increasingly dependent on other professions for relationship building (e.g. software development or social media management). Professionals without forestry background are not likely to share the strong identification with a highly context-specific community, potentially causing severe destabilization of a shared and consistent perception of firm identity. Consequently, exploring digital matchmaking may create tension between professionals with different backgrounds [3].

Mobilizing for Innovation. Our study indicates that conventional matchmakers can actively reinforce multi-sided value creation over time [27] by identifying complementary products and services. For example, Sydved created a new arena for plant suppliers, and thus, enabled new services for forest owners. They also exploited environmental standards to facilitate knowledge transfer for the purpose of novel forestry services and environmental value creation. From a theoretical perspective, Sydved activated complementary resources across the industry to innovate its core business [21].

In contrast, the digital matchmaker seeks to establish cross-industry collaboration with actors sharing an interest in the digital platform [53]. Rather, digital matchmaking is intrinsically unbounded as launching open architectures may generate value creation beyond what is distinguishable beforehand. Essentially, the digital matchmaker's goal is promoting generative exploration, i.e. the particular characteristics of digital technology making them spur further innovation $[55,66]$. Thereby, digital 
matchmakers operate in all the more dynamic ecosystems. In this context, complements tend to be the core of innovation, in the sense that they make the base for business and profit. Becoming a digital matchmaker therefore not only requires new perspectives on innovation, but on firms' core business models.

For a conventional matchmaker like Sydved that has actively constructed and communicated a shared identity with its surrounding ecosystem, we see two potential tensions emerging in mobilizing for innovation. First, the openness and rapid dynamics associated with digital matchmaking may challenge the stability of identity as a wider range of stakeholders share interests in a digital platform and managers seek partnerships outside the familiar ecosystem. Second, external actors' perceptions of what is core about the matchmaker's identity may be in conflict with novel pathways following digitalization. In the Sydved case, the owners' perception of the core mission of a matchmaker like Sydved (i.e. ensure raw material supply) may conflict with arguments for investing in digital platforms, and so, risks becoming a source of inertia [60].

Governing Transactions. Our study suggests that the conventional matchmaker is dependent on brokering for maintaining control of transactions. Therefore, the forest buyers are essentially "brokers" where organizational structures (geographically divided areas and partly decentralized authority) aim to support this role. Here, managers of conventional matchmakers govern by combining contracting (for employment, partnerships etc.) and incentivizing employees to balance "buying" and mill demands. Ultimately, pricing is the key instrument for value capture. While forest buyers are authorized to make individualized offers to forest owners, they need to take predetermined pricing with mills into account.

Digital matchmaking is rather about enabling orchestration where ecosystem actors self-organize [4]. Transactions may be governed through various forms of licensing, but often it has proved more efficient to invest in mechanisms for incentivizing ecosystem actors. In this increasingly distributed ecosystem structure, dynamic pricing can reflect prevailing supply and demand conditions in a given point in time [9].

Brokering versus orchestration entail contradictions that are profoundly challenging from the matchmaker's point of view. When the "broker" role is questioned, the conventional matchmaker may face internal legitimization challenges from professional matchmakers [42], as for example authority for pricing and incentivizing ecosystem actors rather is managed through a digital platform.
For avoiding conflict yet legitimizing new courses of action, existing research point to that selectively coupling shared elements in different organizing logics can be helpful for managing logic plurality [42]. Governing by (re-)incentivizing could be an example of such shared element for a conventional matchmaker in incentivizing professional matchmakers to engage in new pathways and thus, include them in a digitalization trajectory.

Curating Matches. Curation is about reducing the negative consequences of scaling and improving the quality of matches [50]. Ultimately, successful curation strategies require rich information about needs, objectives, and incentives. Since Sydved is a broker - taking direct control over transactions - the negative consequences of scaling are typically hidden from ecosystem stakeholders; forest owners do not see the full range of mills; mills do not see Sydved's portfolio of contracted forest owners. Therefore, curation translates into a matter of increasing efficiency of internal administration. In Sydved, optimizing logistics has been central in reducing the complexities stemming from scaling. Bartering with competitors is a salient tactic where Sydved is curating matches. Scaling for Sydved typically means spatial expansion of the market. Such expansion brings longer and more expensive transports, potentially driving forest owners away to competitors with local presence. For mutual benefit, the firm has established partnerships with competitors' mills, substantially reducing the problems of geographical expansion.

Digital matchmakers exercise curation, "who gets what and why" [49], by improving knowledge and efficiency in this process. Data analytics offer technologies for improved knowledge and software based algorithmic matching for improved efficiency. Essentially, the digital matchmaker can tune transparency for external actors to maximize network effects. What you "see" depends on who you are and how you have engaged with the platform over time. While the basic idea of curation makes sense in conventional as well as digital matchmaking it is clear that practical implementations differ substantially. Where conventional practice tends to focus on resource planning, the digital is concentrating on network effects. The tension we identity in organizing for curating matches is similar to that in relationship building. Alike forest buyers, logisticians is another profession where tensions can emerge as management become dependent on other professions for efficient curation (for example data scientists) [3].

Our study of Sydved paints a substantially different picture of matchmaking than illustrated in digital platform theory. Our distinction between conventional and digital matchmaking indicate that deeply 
institutionalized practices are in change following digitalization. With this study, we make a theoretical contribution to the growing literature on changing organizing logic following digital technology adoption $[2,3,56,10]$. While our in-depth case study approach has provided a rich empirical account of data, we recognize that our findings could be corroborated by complementary studies of conventional matchmakers in other contexts to identify context specific aspects of matchmaking. Further, Table 1 is not to be considered complete but may be complemented in subsequent research. We also believe that longitudinal studies of conventional matchmakers during digitalization are highly interesting research ventures. Such studies can improve knowledge on how to manage (partly) conflicting organizing logics and on implications of adopting identity-challenging technologies, as these are arguably extra difficult to embrace in firms with organizational legacy [61].

\section{References}

[1] R. Adner, "Match your innovation strategy to your innovation ecosystem", Harvard business review, 84 (2006), pp. 98-107.

[2] N. Berente and Y. Yoo, "Institutional contradictions and loose coupling: Postimplementation of NASA's enterprise information system", Information Systems Research, 23 (2012), pp. 376-396.

[3] A. Boonstra, U. Yeliz Eseryel and M. A. G. van Offenbeek, "Stakeholders' enactment of competing logics in IT governance: polarization, compromise or synthesis?", European Journal of Information Systems, 27 (2018), pp. 415-433.

[4] K. J. Boudreau and K. R. Lakhani, "How to manage outside innovation", MIT Sloan Management Review, 50 (2009), pp. 69-76.

[5] A. M. Brandenburger and B. J. Nalebuff, Co-opetition, Crown Business, 2011.

[6] S. Chanias, M. D. Myers and T. Hess, "Digital transformation strategy making in pre-digital organizations: The case of a financial services provider", The Journal of Strategic Information Systems (2018).

[7] K. Charmaz, Constructing grounded theory: A practical guide through qualitative analysis, Sage, 2006.

[8] H. Chen, R. H. Chiang and V. C. Storey, "Business intelligence and analytics: From big data to big impact", MIS quarterly, 36 (2012).

[9] M. K. Chen and M. Sheldon, Dynamic Pricing in a Labor Market: Surge Pricing and Flexible Work on the Uber Platform, Ec, 2016, pp. 455.

[10] W. L. Currie and M. W. Guah, "Conflicting institutional logics: a national programme for IT in the organisational field of healthcare", Journal of Information Technology, 22 (2007), pp. 235-247.

[11] B. Dattée, O. Alexy and E. Autio, "Maneuvering in poor visibility: How firms play the ecosystem game when uncertainty is high", Academy of Management Journal, 61 (2018), pp. 466-498.

[12] M. de Reuver, C. Sørensen and R. C. Basole, "The digital platform: a research agenda", Journal of Information Technology (2017), pp. 1-12.

[13] B. Demil and X. Lecocq, "Neither market nor hierarchy nor network: The emergence of bazaar governance", Organization studies, 27 (2006), pp. 1447-1466.

[14] C. Dhanarai and A. Parkhe, "Orchestrating Innovation Networks", The Academy of Management Review, 31 (2006), pp. 659-669.

[15] B. Eaton, S. Elaluf-Calderwood, C. Sorensen and Y. Yoo, "Distributed tuning of boundary resources: the case of Apple's iOS service system", MIS Quarterly: Management Information Systems, 39 (2015), pp. 217-243.

[16] J. T. Eckhardt, M. P. Ciuchta and M. Carpenter, "Open innovation, information, and entrepreneurship within platform ecosystems", Strategic Entrepreneurship Journal, 12 (2018), pp. 369-391.

[17] T. Eisenmann, G. Parker and M. W. Van Alstyne, "Strategies for two-sided markets", Harvard business review, 84 (2006), pp. 92-101.

[18] D. S. Evans and R. Schmalensee, "The Business That Platforms Are Actually Disrupting", Cambridge Mass.: Harvard Business School (2016).

[19] D. S. Evans and R. Schmalensee, Matchmakers: the new economics of multisided platforms, Harvard Business Review Press, 2016.

[20] R. Friedland and R. R. Alford, "Bringing society back in: Symbols, practices and institutional contradictions", The New Institutionalism in Organizational Analysis (1991), pp. 232-263.

[21] L. Fuentelsaz, E. Garrido and J. P. Maicas, "Incumbents, technological change and institutions: How the value of complementary resources varies across markets", Strategic Management Journal, 36 (2015), pp. 1778-1801.

[22] N. Furr and A. Shiplov, "Buliding the Right Ecosystem for Innovation", MIT Sloan Management Review, 59 (2018), pp. 58-64.

[23] A. Gawer, "Bridging differing perspectives on technological platforms: Toward an integrative framework", Research Policy, 43 (2014), pp. 1239-1249.

[24] A. Gawer and N. Phillips, "Institutional work as logics shift: The case of Intel's transformation to platform leader", Organization studies, 34 (2013), pp. 1035-1071.

[25] A. Ghazawneh and O. Henfridsson, "Balancing platform control and external contribution in third-party development: the boundary resources model", Information Systems Journal, 23 (2013), pp. 173-192.

[26] R. M. Henderson and K. B. Clark, "Architectural innovation: The reconfiguration of existing product technologies and the failure of established firms", Administrative science quarterly (1990), pp. 9-30.

[27] T. Holzmann, K. Sailer and B. R. Katzy, "Matchmaking as multi-sided market for open innovation", Technology Analysis \& Strategic Management, 26 (2014), pp. 1-15.

[28] J. Howells, "Intermediation and the role of intermediaries in innovation", Research policy, 35 (2006), pp. 715-728.

[29] J. Huang, O. Henfridsson, M. Liu and S. Newell, "Growing on Steroids: Rapidly Scaling the User Base of 
Digital Ventures Through Digital Innovation", MIS Quarterly, 41 (2017), pp. 301.

[30] M. Iansiti and R. Levien, "Strategy as ecology", Harvard Business Review, 82 (2004), pp. 68-78.

[31] M. G. Jacobides, C. Cennamo and A. Gawer, "Towards a theory of ecosystems", Strategic Management Journal (2018), pp. 2255-2276.

[32] I. Jeacle and C. Carter, "In TripAdvisor we trust: Rankings, calculative regimes and abstract systems", Accounting, Organizations and Society, 36 (2011), pp. 293309.

[33] M. L. Katz and C. Shapiro, "Network externalities, competition, and compatibility", The American economic review, 75 (1985), pp. 424-440.

[34] D. Koutsikouri, R. Lindgren, O. Henfridsson and D. Rudmark, "Extending Digital Infrastructures: A Typology of Growth Tactics", Journal of the Association for Information Systems, 19 (2018), pp. 1001-1019.

[35] D. A. Levinthal, "Surviving Schumpeterian environments: An evolutionary perspective", Industrial and corporate change, 1 (1994), pp. 427-443.

[36] B. Libert, Y. Wind and M. Fenley, "What Airbnb, Uber, and Alibaba have in common", Harvard business review (2014).

[37] L. Mathiassen, "Designing engaged scholarship: From real-world problems to research publications", Engaged Management Review, 1 (2017).

[38] R. E. Miles and C. C. Snow, "Organizations: New concepts for new forms", California management review, 28 (1986), pp. 62-73.

[39] J. F. Moore, "Predators and Prey - a New Ecology of Competition", Harvard Business Review, 71 (1993), pp. 7586.

[40] S. Nambisan, K. Lyytinen, A. Majchrzak and M. Song, "Digital Innovation Management: Reinventing innovation management research in a digital world", Mis Quarterly, 41 (2017).

[41] T. O'Reilly, WTF?: What's the Future and why It's Up to Us, Random House, 2017.

[42] A. C. Pache and F. Santos, "Inside the hybrid organization: selective coupling as a response to competing institutional-logic.", Academy of Management Journal, 56 (2013), pp. 972-1001.

[43] G. Parker and M. Van Alstyne, "A digital postal platform: Definitions and a roadmap", MIT Center for Digital Business, Working Paper (2012).

[44] G. Parker, M. Van Alstyne and X. Jiang, "Platform ecosystems: How developers invert the firm", MIS Quarterly, 41 (2017), pp. 255-266.

[45] G. G. Parker, M. W. Van Alstyne and S. P. Choudary, "Pipelines, platforms, and the new rules of strategy", Harvard Business Review, 94 (2016), pp. 54-62.

[46] G. G. Parker, M. W. Van Alstyne and S. P. Choudary, Platform Revolution: How Networked Markets Are Transforming the Economy - And How to Make Them Work for You, W. W. Norton \& Company, 2016.

[47] M. E. Porter, Competitive advantage: Creating and Sustaining Superior Performance, Free Press, New York, 1985.

[48] Y. Qiu, A. Gopal and I.-H. Hann, "Logic pluralism in mobile platform ecosystems: a study of indie app developers on the iOS App Store.(Report)", Information Systems Research, 28 (2017), pp. 225.

[49] T. Reay and C. R. Hinings, "Managing the rivalry of competing institutional logics", Organization studies, 30 (2009), pp. 629-652.

[50] A. E. Roth, Who Gets What-and Why: The New Economics of Matchmaking and Market Design, Houghton Mifflin Harcourt, 2015.

[51] A. E. Roth, T. Sönmez and M. U. Ünver, "Kidney exchange", The Quarterly Journal of Economics, 119 (2004), pp. 457-488.

[52] V. Sambamurthy and R. W. Zmud, "Research commentary: The organizing logic for an enterprise's IT activities in the digital era-A prognosis of practice and a call for research", Information systems research, 11 (2000), pp. 105-114.

[53] L. Selander, O. Henfridsson and F. Svahn, "Capability search and redeem across digital ecosystems", Journal of Information Technology, 28 (2013), pp. 183-197.

[54] P. Snickars and R. Fleischer, Den svenska enhörningen: Storyn om Spotify, Mondial förlag, 2018.

[55] F. Svahn, R. Lindgren and L. Mathiassen, Applying Options Thinking to Shape Generativity in Digital Innovation: An Action Research into Connected Cars, 2015, pp. 4141-4150.

[56] F. Svahn, L. Mathiassen and R. Lindgren, "Embracing Digital Innovation in Incumbent Firms: How Volvo Cars Managed Competing Concerns", Management Information Systems Quarterly, 41 (2017), pp. 239-253.

[57] B. Tan, S. L. Pan, X. H. Lu and L. H. Huang, "The Role of IS Capabilities in the Development of Multi-Sided Platforms: The Digital Ecosystem Strategy of Alibaba.com", Journal of the Association for Information Systems, 16 (2015), pp. 248-280.

[58] P. H. Thornton and W. Ocasio, "Institutional logics", The Sage handbook of organizational institutionalism, 840 (2008), pp. 99-128.

[59] A. Tiwana, "Evolutionary Competition in Platform Ecosystems", Information Systems Research, 26 (2015), pp. 266-281.

[60] M. Tripsas, "Technology, identity, and inertia through the lens of "The Digital Photography Company", Organization science, 20 (2009), pp. 441-460.

[61] E. W. Tsang, "Case studies and generalization in information systems research: A critical realist perspective", The Journal of Strategic Information Systems, 23 (2014), pp. 174-186.

[62] M. L. Tushman and P. Anderson, "Technological discontinuities and organizational environments", Administrative science quarterly (1986), pp. 439-465.

[63] G. Walsham, "Interpretive case studies in IS research: nature and method", European Journal of information systems, 4 (1995), pp. 74-81.

[64] Y. Yoo, O. Henfridsson and K. Lyytinen, "Research commentary-the new organizing logic of digital innovation: an agenda for information systems research", Information systems research, 21 (2010), pp. 724-735.

[65] F. Zhu and N. Furr, "Products to platforms: Making the leap", Harvard business review, 94 (2016), pp. 72-78.

[66] J. L. Zittrain, "The generative internet", Harvard Law Review (2006), pp. 1974-2040. 